\title{
A study of comparison of efficacy and side effects of intravenous paracetamol and intravenous diclofenac as a postoperative analgesic
}

\author{
Sharda A. Agrawal*, Surendra D. Nikhate, Manasi M. Thakur, Himadri Bal
}

Department of Obstetrics and Gynaecology, Dr. D. Y. Patil Medical College, Dr. D Y Patil Vidyapeeth, Pimpri, Pune, Maharashtra, India

Received: 05 July 2019

Accepted: 31 July 2019

\section{*Correspondence:}

Dr. Surendra D. Nikhate,

E-mail: hellosun2000@gmail.com

Copyright: $@$ the author(s), publisher and licensee Medip Academy. This is an open-access article distributed under the terms of the Creative Commons Attribution Non-Commercial License, which permits unrestricted non-commercial use, distribution, and reproduction in any medium, provided the original work is properly cited.

\section{ABSTRACT}

Background: A postoperative patient suffers from pain the best relief of which is a clinician's duty. Till date very few studies have been conducted for comparison of paracetamol and diclofenac as analgesics. As a result a comparative study between Paracetamol and Diclofenac was carried out. The aim of the study was to compare the efficacy and side effects of intravenous Paracetamol and intravenous Diclofenac in patients undergoing major abdominal open surgeries in obstetrics and gynaecology. The study was conducted to assess the postoperative visual analogue pain scores (VAS) and total analgesic requirement in the first 24 hours and also to study the total requirement of additional analgesics despite administration of either Paracetamol or Diclofenac in postoperative period.

Methods: 100 patients satisfying the inclusion/exclusion criteria were recruited for the study. They were divided into two groups of 50 each. Group A was given IV Paracetamol 6 hourly for 48 hours starting 2 hours after surgery. Group B was given IV Diclofenac 8 hourly for 48 hours starting 2 hours after surgery. Patients were assessed for pain relief by visual analogue scale (VAS) of zero to ten after 6 hours, 12 hours, 24 hours and 48 hours of surgery by asking the patient to point the position on the $100 \mathrm{~mm}$ scale.

Results: The results revealed that when we compared the VAS scores between the 2 Groups at different time intervals, it showed that at 24 hours and 48 hours VAS score in the Diclofenac Group was significantly less than the Paracetamol Group. The main side effects were nausea and vomiting in both the groups. There was more nausea and vomiting in Diclofenac group compared to Paracetamol group.

Conclusions: It was concluded that at 24 hour and 48 hour pain reduction was more in the Diclofenac group as compared to Paracetamol group, but the side effects were more in the Diclofenac group compared to Paracetamol group.

Keywords: Diclofenac, Paracetamol, Postoperative pain, VAS score

\section{INTRODUCTION}

Galen remarked "Divinum est sedare dolorem" meanings blessed are those who treat pain. The International Association for the Study of Pain (IASP) has aptly defined pain as "an unpleasant sensory and emotional experience associated with actual or potential tissue damage, or described in terms of such damage." Pain causes an increase in the sympathetic response of the body with subsequent rise in heart rate, cardiac work and oxygen consumption. Prolonged pain can lead to reduced physical activity and increased risk of deep vein thrombosis. In addition there can be widespread effects on gut and urinary tract motility which may lead to 
postoperative ileus, nausea, vomiting and urinary retention. Opioids have traditionally been the cornerstone of pharmacotherapy in the management of postoperative pain. A multimodal approach to pain control including a combination of analgesic options such as regional techniques and non-opioid analgesics have shown improved analgesia with early mobilization and reduced opioid side effects in postoperative patients. Currently, the American Society of Anesthesiologists Task Force on Acute Pain Management advocates the use of multimodal analgesia. $^{2}$

Non-steroidal anti-inflammatory drugs (NSAIDS) like diclofenac exert their action via inhibition of prostaglandin (PG) synthesis by inhibiting cyclooxygenase-1 (COX-1) and COX-2 enzymes with relative equipotency while in vivo effects of paracetamol are similar to those of the selective COX-2 inhibitors. ${ }^{3,4}$ An added benefit of paracetamol is its antipyretic action. Injection diclofenac has established its role as an effective post-operative analgesic even for major surgeries. ${ }^{5}$ With the relatively recent availability of an intravenous paracetamol preparation, its use has been revitalized, including the post-operative setting. There has been a recent trend for combining different NSAIDs with Paracetamol for the management of acute postoperative pain but the therapeutic superiority of any combination remains controversial. ${ }^{6,7}$

This trial was conducted to compare the post-operative analgesic effects of diclofenac and paracetamol in patients undergoing major abdominal open surgeries in obstetrics and gynaecology. The aim was to assess the postoperative visual analogue pain scores (VAS) and total analgesic requirement in the first 24 hours and also to study the total requirement of additional analgesics despite administration of either Paracetamol or Diclofenac in postoperative period.

\section{METHODS}

A prospective cohort study was conducted on 100 patients undergoing major open abdominal gynecologic surgery and caesarean section. The cases excluded from the study were: patients having non-specific significant pain in abdomen as a complaint before surgery; patient undergoing gynaecological surgery for endometriosis, severe PID; any medical disorder like tuberculosis, diabetes, liver or kidney disease; any intra operative complication like severe haemorrhage, bowel, bladder injury or cases of severe adhesions. Known case of hypersensitivity or allergy to drug; patient given epidural analgesia; caesarean section for complications like eclampsia or scar rupture were also excluded.

Statistical package Win Pepi was used for calculation of sample size. Assuming a mean VAS of 0.94 (SD 0.725) in the paracetamol group and 0.38 (SD 0.576) in the diclofenac group at 4 hour after surgery with a difference of 0.56 (VAS) at significance level of $5 \%$ and power of
$80 \%$. The sample size worked out to 46 in each group. Assuming $8 \%$ attrition finale sample size came out to be 50 in each group. The patients were divided into two groups of 50 each by simple randomization by chit method. Patient was asked to pick any chit from bowl containing equal number of chits of paracetamol and diclofenac and medicated accordingly. Group A was given IV Paracetamol 6 hourly for 48 hours starting 2 hours after surgery. Group B was given IV Diclofenac 8 hourly for 48 hours starting 2 hours after surgery. Patients were assessed for pain relief by visual analogue scale (VAS) of zero to ten after 6 hours, 12 hours, 24 hours and 48 hours of surgery by asking the patient to point the position on the $100 \mathrm{~mm}$ scale. The far left end indicates "no pain" and has been given score of ' 0 ' and the far right end indicates "severe pain" and was given score of '10'. Following cut off point on the pain VAS had been recommended:

- $\quad$ No pain $(0-4 \mathrm{~mm})$

- $\quad$ Mild pain (5-44mm)

- Moderate pain (45-75mm)

- $\quad$ Severe pain $(75-100 \mathrm{~mm})$.

\section{Statistical analysis}

The adverse effects like nausea and vomiting were noted. Statistical analysis and data had been entered in EXCEL and analyzed using SPSS. Categorical outcome was summarized using proportions and quantitative outcome such as VAS scale was summarized as mean and SD. Appropriate statistical test such as chi-square and related measures ANOVA had been carried out. Prescription to the patient was given on generic name basis and outcome of the study has not been used for any commercial purpose. Ethical committee clearance was obtained before commencing the study.

\section{RESULTS}

The difference in median pain score at different time intervals was analysed with the help of Wilcoxon Sign rank test in SPSS version 16.

There was systematic decrease in median pain score independently in both the groups, with progress of time i.e. from immediate postoperative period to 48 hours later. The extent of this decrease in either group was statistically significant.

Table 1: Distribution of surgical procedures performed.

\begin{tabular}{|lll|}
\hline $\begin{array}{l}\text { Surgery } \\
\text { Performed }\end{array}$ & $\begin{array}{l}\text { Paracetamol } \\
\text { Group }(\mathbf{n}=50)\end{array}$ & $\begin{array}{l}\text { Diclofenac } \\
\text { Group }(\mathbf{n}=50)\end{array}$ \\
\hline Caesarean section & 34 & 32 \\
\hline $\begin{array}{l}\text { Total abdominal } \\
\text { hysterectomy }\end{array}$ & 12 & 14 \\
\hline Staging laparotomy & 4 & 4 \\
\hline
\end{tabular}




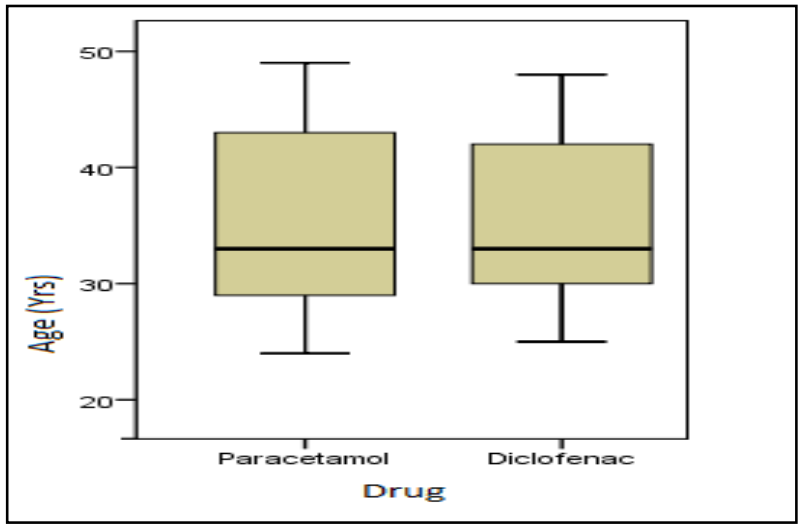

Figure 1: Whisker box plot showing frequency distribution of study samples according to age (years).

Mean age of study sample of Paracetamol and Diclofenac group was almost similar (34 years), with standard deviation of 1 year. Maximum was 49 years and minimum was 24 years in Paracetamol group, while in Diclofenac group maximum was 48 years and minimum was 25 years (Figure 1). Distribution of the surgical procedures was found to be almost similar in both the groups (Table 1).

Table 2: Median VAS scores at various timelines in the 2 groups.

\begin{tabular}{|lll|}
\hline Timeline & $\begin{array}{l}\text { Paracetamol } \\
\text { (Median VAS) }\end{array}$ & $\begin{array}{l}\text { Diclofenac } \\
\text { (Median VAS) }\end{array}$ \\
\hline $\begin{array}{l}\text { Immediate post- } \\
\text { operative period } \\
\text { (Baseline) }\end{array}$ & 8 & 8 \\
\hline 6 hours & 6 & 5 \\
\hline 12 hours & 4 & 4 \\
\hline 24 hours & 3 & 2 \\
\hline 48 hours & 1 & 0 \\
\hline
\end{tabular}

(Wilcoxon Sign rank test $\mathrm{p}$ value $<0.01$ )

Table 3: Median VAS Score comparison in the Paracetamol and Diclofenac groups.

\begin{tabular}{|llllll|}
\hline Kruskal Wallis Test & & & & & \\
& Immediate post-operative period & $\mathbf{6}$ hours & $\mathbf{1 2}$ hours & $\mathbf{2 4}$ hours & $\mathbf{4 8}$ hours \\
\hline Chi-square & 0.037 & 2.505 & 0.229 & 27.256 & 6.486 \\
\hline Degree of freedom & 1 & 1 & 1 & 1 & 1 \\
\hline Asymptotic significance & 0.847 & 0.113 & 0.632 & $\mathbf{0 . 0 0 0}$ & $\mathbf{0 . 0 1 1}$ \\
\hline Grouping Variable: drug code & 1=Paracetamol, 2=Diclofenac & \\
\hline
\end{tabular}

The second step was to compare the pain scores between the 2 groups at each time interval. When we compared both the groups, initial pain reduction, in immediate postop, 6 hours and 12 hours, was almost similar but there was significant difference between the 2 groups in pain scores at 24 and 48 hours with the score being significantly lower in Diclofenac group (Table 2).

Kruskal Wallis test (non-parametric test) was applied to see difference in median VAS score between Paracetamol and Diclofenac group at different time intervals. Inputs of both groups were put into software SPSS version 16 and results were tabulated. There was statistically significant difference in median at 24 hour (p 0.000) and 48 hour (p 0.011). It meant at 24 hour and 48 hour pain reduction was more in the Diclofenac group as compared to Paracetamol group (Table 3).

Some of the patients complained of intolerable pain even after receiving the scheduled analgesics, mostly on the postoperative evening, late at night. These cases were given Inj. Fortwin (Pentazocin) as a rescue analgesic. However rescue analgesia required was one dose only in both groups. There were $6(12 \%)$ patients in Paracetamol Group and $3(6 \%)$ patients in Diclofenac Group who needed rescue analgesia on the post-operative evening (Figure 2).

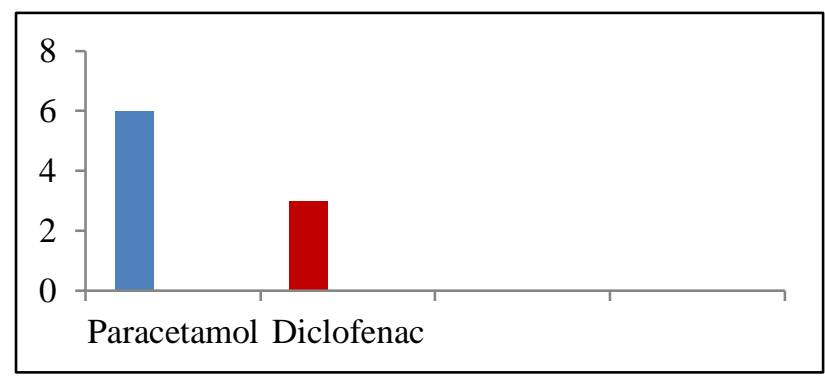

Figure 2: Bar diagram showing requirement of rescue analgesia in both groups.
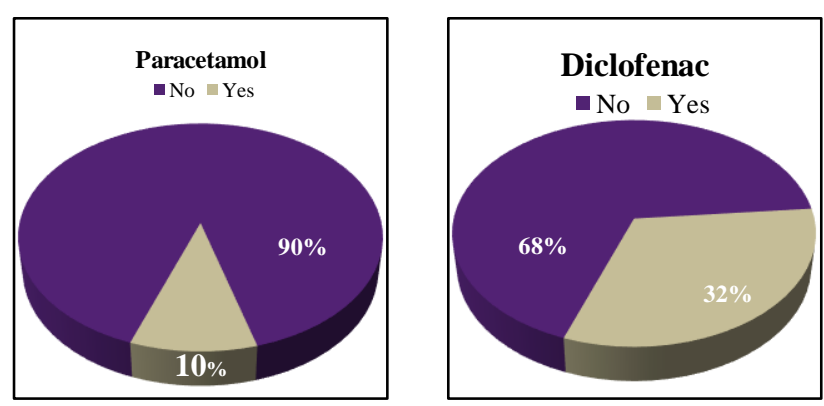

Figure 3: Pie chart showing frequency distribution of study samples according to side effect of the drugs. 
The main side effects were nausea and vomiting in both the groups. The pie chart (Figure 3) shows that, there was more nausea and vomiting in Diclofenac group (32\%) compared to Paracetamol group (10\%) (Figure 3).

\section{DISCUSSION}

Post-operative pain is a subjective sensation varying from person to person. This depends upon psychosomatic personality, age and type of operation. Relief of pain is of foremost importance to the patient as it causes not only discomfort but also increases the risk of complications. Various pharmacological and non-pharmacological approaches are being used to get relief of postoperative pain and investigations are still under way to find out the best suitable method or pharmacological agent for postoperative analgesia.

Paracetamol is used in the management of pain, alone or in combination with other analgesic drugs. At recommended dosages, paracetamol is devoid of serious side effects. Paracetamol is not associated with the increased incidence of nausea, vomiting and respiratory depression which are seen with the use of opioids, or any deleterious gastrointestinal, hematological, renal or cardiovascular effects associated with NSAIDs, including selective COX-2 inhibitors.

Most published studies in the literature have either considered only caesarean section cases or major gynecological surgical cases, but none of the studies have included both these groups simultaneously.

There are numerous studies in literature which have evaluated efficacy of Paracetamol or NSAID as an adjunct to Morphine or Tramadol with the aim of reducing the dose and countering the side-effects of the latter drugs. However few studies have compared the effects of Paracetamol or Diclofenac as post-operative analgesic and using opioids only as last line of therapy or 'Rescue Medication' for pain relief.

The Paracetamol Group showed a significant change in its Median VAS score from immediate postoperative period till 48 hour in its own group of patients $(p<0.05)$. Similar results were seen with Diclofenac Group also. i.e reduction of all the three time based scores were statistically significant compared to the Baseline score within the group itself $(\mathrm{p}<0.05)$. However when we compared the VAS scores between the 2 Groups at different time intervals, it showed that at 24 hours and 48 hours VAS score in the Diclofenac Group was significantly less than the Paracetamol Group. It means at 24 hour and 48 hour pain reduction is more in the Diclofenac group as compared to Paracetamol group.

A non-randomized study was carried out in 2015 by AshimaTaneja, Vidhushi, Tanudeep Kaur et al in which the pain relief was seen in $32 \%$, in group I (Paracetamol) and $30 \%$ in group II (Diclofenac) after 24 hours; $40 \%$ and $50 \%$ respectively after 48 hours. $^{8}$

In the study done by Debashish Paul, Sachin Narayan Kulkarni et al in the year 2015 it was found that there was significant reduction of VAS pain score at $0,2,6$ and 12 hours (p-values 0.0005, 0.003, 0.001, 0.0005 respectively) in laparoscopic cholecystectomy, and which also commented Paracetamol was better than Diclofenac at 6 and 12 hours. $^{9}$

In a randomized double-blind study designed by Sarika and Rachna Wadhwa in 2015 to compare preemptive analgesic efficacy of Acetaminophen, Diclofenac and combination of both, administered orally in patients undergoing elective modified radical mastectomy, the Global satisfaction score (GSC) as regard to postoperative pain at 24 hours were significantly better in Diclofenac group as compared to Acetaminophen. ${ }^{10}$

The initial pain score values of the Paracetamol group were higher than that of Diclofenac group in study done by Ayan M et al in the year 2013 in emergency room with cases of primary dysmenorrhea. ${ }^{11}$ Following treatment, in the 10th and 30th minutes, the scores were lower in Paracetamol group compared to Diclofenac $(p=0.00)$. Hence this study showed Paracetamol is more efficient than Diclofenac in the treatment of primary dysmenorrhea.

A randomized, double-blind study conducted in the year 2014 by Anirban Pal et al showed a significant decrease in VAS score in Diclofenac alone and Paracetamol Diclofenac Groups compared to Paracetamol alone between 4 and 12 hours post-operatively. The combined Paracetamol - Diclofenac Group showed no significant advantage when compared to Diclofenac alone, proving the superiority of Diclofenac. Similar superiority of Diclofenac was also found in the study. ${ }^{12}$

Kumari UR et al in 2016 did a single-blind randomized controlled interventional study and compared the analgesic efficacy and side effect profile of Paracetamol versus Tramadol in women undergoing caesarean section. ${ }^{13}$ The authors found pain scores were low in both groups across various time interval except at 6 hours in Paracetamol group $(\mathrm{p}=0.673)$ and at 8 hours in Tramadol group $(\mathrm{p}=0.194)$. Requirement for rescue analgesia was comparable in both the groups $(16 \%$ vs. $10 \%, \mathrm{p}=0.372)$. However maternal side effects were more in Tramadol group ( $8 \%$ vs. $34 \%, \mathrm{p}=0.001)$. The authors concluded that both Paracetamol and Tramadol achieve satisfactory pain control after cesarean section but Tramadol causes significant side effects in mother compared to Paracetamol.

A positive aspect of the study population was that patients having non-specific significant pain in abdomen as a complaint before surgery and patients undergoing 
surgery for endometriosis or severe PID, which are also associated with pain as a symptom, have been excluded.

\section{CONCLUSION}

Both Paracetamol and Diclofenac with passage of time in this study showed significant reduction in pain score. We found that pain reduction in both groups did not have significant difference at 6 and 12 hour which meant both drugs had similar efficacy in reducing pain within this time frame. Further comparison of the VAS scores of the 2 Groups in the study showed that in the Diclofenac Group the score was significantly less at 24 hours and 48 hours compared to the Paracetamol Group. The requirement of rescue analgesia with pentazocine, when pain was not effectively controlled with the drugs under study, was more with Paracetamol. The side effects were mainly nausea and vomiting and this was more in the Diclofenac group.

To conclude, both Paracetamol and Diclofenac can be safely used for post-operative analgesia. However analgesic efficacy of Diclofenac was found to be more in the study though with a slight increased incidence of minor side effects. The ultimate choice of analgesia will have to be decided by the treating surgeon.

Funding: No funding sources

Conflict of interest: None declared

Ethical approval: The study was approved by the Institutional Ethics Committee

\section{REFERENCES}

1. Merskey NB, Bogduk. N. Classification of chronic pain, international association for the study of pain task force on taxonomy. 2nd ed. Seattle. IASP Press. 1994:209-214.

2. Ashburn MA, Caplan RA, Carr DB. Practice guidelines for acute pain management in the perioperative setting: an updated report by the American Society of Anesthesiologists Task Force on acute pain management. Anesthesiology. 2004;100(6):1573-81.

3. Gan TJ. Diclofenac: An update on its mechanism of action and safety profile. Curr Med Res Opin. 2010;26(7):1715-31.

4. Graham GG, Scott KF. Mechanism of action of paracetamol. Am J Ther. 2005;12(1):46-55.

5. Mcnicol ED, Tzortzopoulou A, Cepeda MS, Francia MB, Farhat T, Schumann R. Single-dose intravenous paracetamol or propacetamol for prevention or treatment of postoperative pain: A systematic review and meta-analysis. Br J Anaesth. 2011;106(6):76475.

6. Rømsing J, Møiniche S, Dahl JB. Rectal and parenteral paracetamol, and paracetamol in combination with NSAIDs, for postoperative analgesia. Br J Anaesth. 2002;88(2):215-26.

7. Ong CK, Seymour RA. An evidence-based update of the use of analgesics in dentistry. Periodontol. 2008;46(1):143-64.

8. Ashima T, Vidhushi M, Kaur T. Comparative study on the effect of paracetamol, diclofenac and their combination in post operative pain relief of cesarean section. JK Science. 2015;17(1):30.

9. Paul D, Jacob M, Narayan S. Comparative evaluation of efficacy of intravenous paracetamol and intravenous diclofenac as post-operative analgesia in laparoscopic cholecystectomy. Int $\mathrm{J}$ Biomed Research. 2015;6(7):482-7.

10. Sarika, Wadhwa R. Research article a randomised double blind study comparing preemptive analgesic efficacy of oral acetaminophen, diclofenac and combination of acetaminophen and diclofenac in modified radical mastectomy surgery. Int $\mathrm{J}$ Recent Scientific Res. 2015;6(10):6702-6706.

11. Ayan M, Taş U, Söğüt E, Arıcı S, Karaman S, Esen M, Demirtürk F. Comparing efficiencies of diclofenac sodium and paracetamol in patients with primary dysmenorrhea pain by using Visual Analog Scale. Agri. 2013;25(2):78-82.

12. Pal A, Biswas J, Mukhopadhyay P, Sanyal P, Dasgupta S, Das S. Diclofenac is more effective for post-operative analgesia in patients undergoing lower abdominal gynaecological surgeries: A comparative study. Anesth Essays Res. 2014;8(2):192-6.

13. Kumari UR, Zutshi V, Patel M, Marwah S. Analgesic efficacy of intravenous paracetamol versus intravenous tramadol after caesarean section: a single blind randomized controlled study. Int J Repro Contracep Obst Gyn. 2016;5:4285-9.

Cite this article as: Agrawal SA, Nikhate SD, Thakur MM, Bal H. A study of comparison of efficacy and side effects of intravenous paracetamol and intravenous diclofenac as a postoperative analgesic. Int J Reprod Contracept Obstet Gynecol 2019;8:3684-8. 